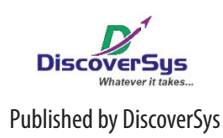

Published by DiscoverSys

\section{The provision of promotive and preventative healthcare services by private primary care physicians in the era of the national health insurance program}

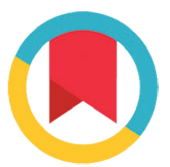

CrossMark

\author{
Ketut Ary Diana Artha, ${ }^{1{ }^{*}}$ I Ketut Suarjana, ${ }^{2,3}$ Pande Putu Januraga ${ }^{2,3}$
}

\section{ABSTRACT}

Background and purpose: In addition to their duties in addressing the curative and rehabilitative needs of the community, private primary care physicians $(P C P)$ play an important role in providing promotive and preventative healthcare services. This study aims to determine the behaviours, enabling and inhibiting factors involved with the provision of promotive and preventative services by $P C P$ in the era of national health insurance (JKN) implementation.

Methods: This research is a mix method study using a combination of quantitative and qualitative approaches. Quantitative surveys were conducted with all PCPs already in working collaboration with the Social Security Administering Agency (BPJS) in the Denpasar City area (61 people). Data analysis techniques used descriptive techniques in order to explore the kinds of promotion and preventative services provided by PCPs. Qualitative research was conducted through indepth interviews of 8 informants selected by purposive sampling and analyzed thematically to discover the enabling and inhibiting factors of the provision of promotive and preventative services by PCPS.
Results: The results showed that $91.8 \%$ of PCPs did perform promotive and preventative services in their practice site. PCPs who did not carry out promotive and preventative services demonstrate perceptions, beliefs and motivations categorized as low and weak as well as attitudes that do not support the implementation of such services. Enabling factors of promotion and preventative services by PCPs, include among others, quality of facilities and infrastructure, the receipt of awards from BPJS and capitation systems that benefit physicians financially. Inhibiting factors include a low willingness of the patient to carry out doctor's advice, limitations in the PCPs work time and limited funds to perform preventative/ promotive services.

Conclusions: Promotive and preventative services are not being optimally carried out by PCPs in Denpasar. This is due to the low willingness of the patients, the limited time of the doctor, and the limited allocated funds for promotive and preventative services and low capitation.

Keywords: Social Security Administering Agency (BPJS), private primary care physician (PCP), national health insurance (JKN), promotive and preventative services.

Cite This Article: Artha, K.A.D., Suarjana, I.K., Januraga, P.P. 2017. The provision of promotive and preventative healthcare services by private primary care physicians in the era of the national health insurance program. Public Health and Preventive Medicine Archive 5(2): 140-146. D01:10.15562/phpma. v5i2.29

${ }^{1}$ Denpasar District Health Office Bali,

2Public Health Postgraduate Program Udayana University, ${ }^{3}$ School of Public Health Faculty of Medicine Udayana University

${ }^{*}$ Correspondence to: Ketut Ary Diana Artha, Denpasar District Health Office Bali ary_djanger@yahoo.co.id

\section{INTRODUCTION}

Private primary care physicians (PCPs) can be instrumental in the provision of promotive and preventative services, along with curative and rehabilitative services in the era of national health insurance (JKN). The promotional and preventative services referred to in the JKN program include individual health counseling, primary immunization, family planning counseling, specific health screening services in order to ensure early disease detection and prevent further health impact. ${ }^{1}$

The UK National Health Service (NHS) program illustrates the important role of PCPs in promoting health, preventing illness, providing counseling and advice and appropriate interventions. The success of this service has an impact on the total decline in health expenditure in the country. ${ }^{2}$
The payment system with capitation which has been adopted in Indonesia should be able to encourage physicians to provide counseling services and individual counseling to patients in addition to proper diagnostic and treatment. This is part of promotive and preventative efforts, that aim to suppress the morbidity rate thereby reduce the numbers of visits to the primary care facility. ${ }^{3}$ Social Security Administering Agency (BPJS) health data shows that the ratio of referrals in PCP for JKN patients in Denpasar City increased from $8.26 \%$ in 2014 to $8.48 \%$ in $2015 .{ }^{4}$ This increase in referral ratio indicates that primary care facilities are neglecting to apply their energies into promotive work. Undeniably, promotive services play a crucial function in supporting the continuity of the JKN program, to prevent the expenditure of resources and ensure program sustainability. ${ }^{5}$ 
Research on the implementation of promotive efforts by PCPs in the JKN era has not been conducted. This study aims to determine the behaviours, enabling and inhibiting factors affecting the implementation of preventative/promotive services by PCPs in the era of JKN in Denpasar.

\section{METHODS}

This research is a mix methods study adopting a sequential explanatory model. Quantitative data collection and analysis was conducted first then followed by collecting and analyzing qualitative data to strengthen the results of the earlier quantitative research. ${ }^{6}$ Quantitative data was collected through a survey that was descriptive explorative with up to 61 respondents, and sample was determined using the total population sampling method. Qualitative data was obtained through in-depth interviews of 8 informants selected by purposive sampling. This research was conducted with PCPs who are working with BPJS in Denpasar City from March to April 2017. Before the interview was conducted, every respondent and participant was provided with an information sheet and signed an informed consent.

Analysis of quantitative data used the descriptive approach using Stata SE 12.1 to discover the range of promotion and preventative services provided by PCPs. Qualitative data analysis was conducted using thematic analysis to understand the enabling and inhibiting factors for PCPs in the implementation of preventative/promotive services. This research obtained ethical clearance from the Ethics Committee of Faculty of Medicine Udayana University/Sanglah General Hospital Denpasar.

\section{RESULTS}

\section{Quantitative research results}

The average age of respondents is 47 years with the youngest age 27 years old and oldest at 73 years old, $52.46 \%$ male, $57.38 \%$ undergraduate and $67.21 \%$ with 11-15 years of practice.

Table 1 shows that the proportion of PCPs who did not perform promotive and preventative services was greater among male PCPs $(90.63 \%)$, $100 \%$ among respondents who were $<30$ years old, $94.29 \%$ among whom were first level graduate doctor and $100 \%$ among those who had been practicing for 1- 4 years.

Table 2 shows that the proportions of PCPs that did not perform promotive and preventative services are higher (100\%) among those who have perceptions, beliefs and motivations less. In addition, PCPs who display an unsupportive attitude and did not perform promotive and preventive sercices amounted to $97.56 \%$.
Table 3 indicates that the PCPs ability/motivation to carry out preventative/promotive work is impacted by lack of existing regulations (94.12\%), lack of related facilities (92.59\%), lack of appropriate equipment (96.43\%), lack of anatomy models (93.62\%), lack of pertinent flipcharts (94.74\%), and lack of health promotion video media (95\%). While the proportion of PCPs who do not carry out promotive and preventative services is smaller among PCPs who do not store relevant leaflets $(80 \%)$, and the percentage of PCPs who do not store relevant posters is $0 \%$ and PCPs not in possession of relevant manuals is equivalent to $91.67 \%$.

\section{Qualitative research results}

The results of qualitative research are presented in the form of narrative based on the results of in-depth interviews with 8 respondents. The age range of informants is between 36 to 64 years and the majority are post-graduate and have been practicing for between 11-15 years. Some themes derived from the process of coding and sub-theme determination of qualitative data collected among others are presented below.

\section{PCP's perceptions of promotive and preventative services in the era of JKN}

Most informants do not have the same perception on what are considered promotive and preventative services that must be implemented by the PCP. Some informants stated that promotive and preventative services include counseling, IEC and health information promotion. Some other informants stated that promotive and preventative services also include home visits, early detection and formation of the Chronic Disease Management Program groups. This can be seen from the excerpts of interviews below.

".......promotive services include handing out IEC, and preventative is more action related, right? To address their symptoms, to cure their illness?". (PCP1)

"Promotive preventive is more than giving information, yes for example providing information to the family and care givers... also to carry out home visits etc...". (PCP2)

“... counseling, yes,....conduct counselling, and also education...working with the disease management unit..." (PCP4)

"...... Preventive promotive if we consider the general definition, about follow up, promote positive health strategies especially the field of health in the prevention of a disease...". (PCP7) 
Table 1 Behaviour of PCPs in preventative/promotion service provision in the JKN era based on demographic characteristics

\begin{tabular}{|c|c|c|c|}
\hline \multirow{3}{*}{$\begin{array}{l}\text { Demographic } \\
\text { characteristics }\end{array}$} & \multicolumn{2}{|c|}{ Behaviour } & \multirow{3}{*}{$\begin{array}{l}\text { Total } \\
\text { n (\%) }\end{array}$} \\
\hline & Conducted & Not conducted & \\
\hline & n (\%) & n (\%) & \\
\hline \multicolumn{4}{|l|}{ Sex } \\
\hline Male & $29(90.63)$ & $3(9.38)$ & $32(100)$ \\
\hline Female & $27(93.10)$ & $2(6.90)$ & $29(100)$ \\
\hline \multicolumn{4}{|l|}{ Age } \\
\hline$<30$ years & $3(100)$ & $0(0.00)$ & $3(100)$ \\
\hline $31-60$ years & $47(92.16)$ & $4(7.84)$ & $51(100)$ \\
\hline$>60$ years & $6(85.71)$ & $1(14.29)$ & $7(100)$ \\
\hline \multicolumn{4}{|l|}{ Education } \\
\hline Undergraduate & $33(94.29)$ & $2(5.71)$ & $35(100)$ \\
\hline Post-graduate & $23(92.00)$ & $2(8.00)$ & $25(100)$ \\
\hline Doctoral & $0(0.00)$ & $1(100)$ & $1(100)$ \\
\hline \multicolumn{4}{|l|}{ Length of practice } \\
\hline $1-4$ years & $8(100)$ & $0(0.00)$ & $8(100)$ \\
\hline 5-10 years & $11(91.67)$ & $1(8.33)$ & $12(100)$ \\
\hline $11-15$ years & $37(90.24)$ & $4(9.76)$ & $41(100)$ \\
\hline
\end{tabular}

Table 2 PCPs behaviours in preventative/promotion service provision in the JKN era based on internal factors

\begin{tabular}{|c|c|c|c|}
\hline \multirow[b]{3}{*}{ Internal factors } & \multicolumn{2}{|c|}{ Behaviours } & \multirow{3}{*}{$\begin{array}{l}\text { Total } \\
\text { n (\%) }\end{array}$} \\
\hline & Not conducted & Conducted & \\
\hline & n (\%) & n (\%) & \\
\hline \multicolumn{4}{|l|}{ Perception } \\
\hline Positive perception & $48(90.57)$ & $5(9.43)$ & $53(100)$ \\
\hline Lacking perception & $8(100)$ & $0(0.00)$ & $8(100)$ \\
\hline \multicolumn{4}{|l|}{ Belief } \\
\hline Strong belief & $35(87.50)$ & $5(12.50)$ & $40(100)$ \\
\hline Weak belief & $21(100)$ & $0(0.00)$ & $21(100)$ \\
\hline \multicolumn{4}{|l|}{ Motivation } \\
\hline Strong motivation & $39(88.64)$ & $5(11.36)$ & $44(100)$ \\
\hline Weak motivation & $17(100)$ & $0(0.00)$ & $17(100)$ \\
\hline \multicolumn{4}{|l|}{ Attitude } \\
\hline Supportive & $16(80.00)$ & $4(20.00)$ & $20(100)$ \\
\hline Unsupportive & $40(97.56)$ & $1(2.44)$ & $41(100)$ \\
\hline
\end{tabular}

The difference of informants' perceptions is not only because the different levels of education but is also possibly caused by the lack of frequency of promotion/information delivery conducted by BPJS as the managing body of JKN to PCPs related to promotion and preventative services. This is reflected in the respondent's statements below. "if perhaps they understood better the role and purpose of preventative/promotive work they would be more invested in carrying it out..." (PCP4)

"Yes. Promotion/information delivery happens but never routinely only once or twice and not intensive". (PCP3)

"It depends on scheduling, if we can attend the sessions we will, especially doctors who collaborate with BPJS “. (PCP4)

\section{PCP's attitude towards promotive and preventative service implementation in the JKN era}

Attitude includes the readiness of respondents regarding the implementation of promotive and preventative services. This attitude is influenced by knowledge and beliefs. Most of the informants revealed that the knowledge that doctors have is very influential on the attitude of the PCP in the implementation of promotive and preventative services. This is reflected in the informants statements below.

"Sure .... the more we understand about the function of preventive/promotive work, the more motivated we would be". (PCP4)

"If we know about promotive/preventive efforts then yes, we would be more invested... knowledge is influential, but I personally already have quite a bit of knowledge from my public health background......(PCP8)

It is evident that the informants with the higher personal understanding of the function of preventative/promotive work will be more motivated. Informants believe that carrying out promotive and preventative services helps to reduce the number of patient visits so economically this is more profitable. Promotional and preventative services are also one indicator of services that must be implemented by the PCP. Respondent's statement about PCP's beliefs on promotive and preventative services is presented as follows.

"Yes when we think about the benefits of conducting preventative and promotive work, especially when we talk about economics..." (PCP1)

"We have to be optimistic of the benefits....it is one of our indicators.... if not there should be ramifications..." (PCP7). 
Table 3 PCP behaviours in preventative/promotion service provision in the JKN era based on external factors

\begin{tabular}{|c|c|c|c|}
\hline \multirow[b]{3}{*}{ External factors } & \multicolumn{2}{|c|}{ Behaviours } & \multirow{3}{*}{$\begin{array}{l}\text { Total } \\
\text { n (\%) }\end{array}$} \\
\hline & Not conducted & Conducted & \\
\hline & n (\%) & n (\%) & \\
\hline \multicolumn{4}{|l|}{ Regulations } \\
\hline Supporting & $8(80.00)$ & $2(20,00)$ & $10(100)$ \\
\hline Not supporting & $48(94.12)$ & $3(5.88)$ & $51(100)$ \\
\hline \multicolumn{4}{|l|}{ Facilities } \\
\hline Existing & $31(91.18)$ & $3(8.82)$ & $34(100)$ \\
\hline Not existing & $25(92.59)$ & $2(7.41)$ & $27(100)$ \\
\hline \multicolumn{4}{|l|}{ Equipment } \\
\hline Existing & $2(40.00)$ & $3(60.00)$ & $5(100)$ \\
\hline Not existing & $54(96.43)$ & $2(3.57)$ & $56(100)$ \\
\hline \multicolumn{4}{|l|}{ Anatomy models } \\
\hline Existing & $12(85.71)$ & $2(14.29)$ & $14(100)$ \\
\hline Not existing & $44(93.62)$ & $3(6.38)$ & $47(100)$ \\
\hline \multicolumn{4}{|l|}{ Flipchart } \\
\hline Existing & $38(90.48)$ & $4(9.52)$ & $42(100)$ \\
\hline Not existing & $18(94.74)$ & $1(5.26)$ & $19(100)$ \\
\hline \multicolumn{4}{|c|}{ Health promotion videos } \\
\hline Existing & $18(85.71)$ & $3(14.29)$ & $21(100)$ \\
\hline Not existing & $38(95.00)$ & $2(5.00)$ & $40(100)$ \\
\hline \multicolumn{4}{|l|}{ Leaflets } \\
\hline Existing & $52(92.86)$ & $4(7.14)$ & $56(100)$ \\
\hline Not existing & $4(80.00)$ & $1(20.00)$ & $5(100)$ \\
\hline \multicolumn{4}{|l|}{ Posters } \\
\hline Existing & $56(93.33)$ & $4(6.67)$ & $60(100)$ \\
\hline Not existing & $0(0.00)$ & $1(100)$ & $1(100$ \\
\hline \multicolumn{4}{|c|}{ Health promotion materials } \\
\hline Existing & $23(92.00)$ & $2(8.00)$ & $25(100)$ \\
\hline Not existing & $33(91.67)$ & $3(8.33)$ & $36(100)$ \\
\hline
\end{tabular}

\section{Promotive and preventative service activities at PCPs in the JKN era}

Most informants stated that promotive and preventative activities carried out are in the form of information, education and communication (IEC), chronic disease services and home visits. The description of the respondent's statement is written as follows.

"We distribute IEC about chronic disease particularly when we conduct home visits..." (PCP1)

"...it is more about educating the patient so that they don't get sick in the first place..." (PCP3)

"..... I have established groups dealing with chronic disease...conduct home visits too but not regularly...." (PCP4) ".....we carry out screening, pap smears, health questionnaires, about diabetes and the like, hypertension, and also the chronic disease work...." (PCP7)

These activities can not all be optimally implemented. This is due to several obstacles to the implementation of the chronic disease management program, as reflected in the statement presented by informants below.

"A lot of things we do are not necessarily carried out to the maximum as sometimes the patient gets scared off" (PCP1)

"It is hard to get the implicated patients to get together as they are all busy with their own activities..." (PCP2)

The above statement indicates that there are obstacles that prevent the chronic disease program activities from running optimally for instance the lack of response, the characteristics of informants who are more in productive age and difficulty determining the timing of the implementation of activities. Whereas according to most informants, the BPJS has provided a special fund for the implementation of chronic disease management activities, as described below.

"....oh there are for chronic disease management related activities, for instance funds to buy refreshments for patients etc" (PCP4)

"There are funds for refreshments, around 200, but no extra salary, for aerobics there was some funds to pay the instructor..." (PCP7)

Most informants stated that facilities and infrastructure for promotive and preventative activities are available, but do not fully cover implementation. Some excerpts from interviews with informants clarify this.

"Yes there is some money but not enough to cover everything, for equipment for family planning work for example..." (PCP6)

"Equipment we provide, but we get some subsidies from BPJS, but we need funds for banners, leaflets etc..." (PCP7)

The results of the interviews also show that the BPJS rarely monitor the implementation of promotive and preventative services implemented. This impacts greatly on the implementation of promotive and preventative services. The following statements reflect this. 
"No. Theoretically they should monitor every 3 months, we get color graded, but this doesn't happen..." (PCP6)

\section{Regulations on promotive and preventative service implementation in the JKN era}

Most informants argue that enforcement of regulations on promotive and preventative services are unclear. The following statements echo this.

"Hmm...we need to explore this more....these kinds of approaches are never prioritized...... we need to reconsider what kinds of mechanisms are in place, what support will be provided by BPJS...how will this all be paid for..." (PCP7)

Unclear enforcement are reflected in the fact that these can change at any time and there are no clear sanctions against violations of existing regulations. For instance:

"There are sanctions, there are rules, but it is also up to us to update information, and we need to be updated too if there are any changes put in place..." (PCP2)

"Oh... if we don't do the work we are penalized... that is bullshit...let's see what happens in a couple of years..." (PCP6)

\section{Enabling factors of promotive and preventative service implementation in the JKN era}

There are several factors that drive the implementation of these services. Most of the informants suggested that factors that enable PCP to implement promotive and preventative services include physician motivation, facilities and infrastructure, rewards, regulations and a clear and solid capitation system.

Strong personal motivation from doctors to help create a healthy and prosperous society is one of the motivators for doctors to carry out promotive and preventative services

"Hmm... well it comes from my internal motivation to help contribute to a healthy and prosperous society..." (PCP7)

Available facilities and infrastructure are also factors that encourage doctors to carry out promotive and preventative services.

"Our field of work includes preventative and promotive support for the community.... but is also dependent on the equipment we have..."(PCP8)
Rewards from BPJS in the form of invitation to participate in the primary service jamboree for PCP is of course a motivator encouraging the doctor to carry out promotive and preventative services.

"We get money if we attend the jamboree but I am not sure either..." (PCP6)

The capitation system imposed by BPJS for health financing in primary care facilities strongly encourages doctors to carry out promotive and preventative services. This is reflected in the following statements.

"...it is part of our commitment with BPJS....the second theory is that through conducting preventative and promotive work we will inevitably reduce the number of people getting sick, thereby reduce overall costs" (PCP2)

\section{Factors inhibiting the implementation of promotive and preventative services in the era of JKN}

Inhibiting factors are also evident in the implementation of promotive and preventative services. Most informants argue that the factors that inhibit PCP to implement promotive and preventative services include patient's willingness, time, funds and the amount of capitation.

The lack of willingness of the patient to follow the doctor's advice becomes one of the inhibitors of doctors to carry out promotive and preventative services.

"Obstacles include the patient themselves....the willingness of the patient...for instance patients understand that they shouldn't smoke, but they do anyway..." (PCP1)

Time restrictions also impede preventative and promotive efforts.

"Time is a big factor. And the cooperation of the public" (PCP2)

Limited funding provided for promotive and preventative services outside capitation is also an inhibiting factor.

"Funds are unquestionably a factor..." (PCP3)

The small nominal capitation received by doctors per patient every month also discourages doctors to carry out promotive and preventative services.

"Yes capitation is low. We will go bankrupt if things continue this way..." (PCP5) 


\section{DISCUSSION}

The results indicated that $86.89 \%$ PCP have a positive perception, $65.57 \%$ PCP have strong beliefs and $72.13 \%$ PCP have strong motivation towards providing promotion and preventative service in the JKN era. On the other hand, there are also PCPs that view the initiatives relatively unfavourably up to $67.21 \%$ and $83.61 \%$ of PCP stated that current regulations do not support promotive and preventative services. The results of study also indicate that PCPs who do not provide preventative/promotion services in the JKN era is $91.80 \%$ overall. This shows that although PCP perceptions, motivations and beliefs are demonstrably positive, it does not necessarily shape attitudes and behaviours that support promotive and preventative services. Unclear regulations, time restrictions and funding factors including low capitation rates may cause PCPs become disinterested and reluctant to implement promotive and preventative services.

There are several other studies include research conducted in Catalan, Spain in 2005, which found that more than $70 \%$ of doctors and nurses considered the promotion of physical activity as very important. As many as $88 \%$ of doctors and nurses rarely promote physical activity, 55\% of physicians and $46.1 \%$ of nurses stated that it was often not particularly conducive to promote exercise programs for within the clinic. ${ }^{7}$ Surveys conducted in Germany in 2012 discovered that $26.9 \%$ of respondents reported that they felt their knowledge was inadequate to provide counseling. As many as $36.7 \%$ of respondents felt unsuccessful in motivating their patients to increase physical activity and by $67.6 \%$ felt they were unable to do so. ${ }^{8}$

The result of research also indicates that there are extenuating factors that prevent PCPs in the implementation of promotive and preventative services. These factors include low willingness of the patient to carry out doctor's advice, limited time to perform promotive and preventative services, limited funds available for promotive and preventative services and the small amount of capitation per participant per month received by the doctor.

This is in line with a study conducted in England in 1998 stating that the obstacles experienced by doctors and nurses in promoting physical activity include time constraints, weak reimbursement system, lack of implementation guidelines, counseling failures, lack of appropriate training and the absence of a coordinated and systematic approach in daily practice. ${ }^{9}$

Another study conducted in Germany in 2010 found that most of the barriers identified for prevention services were associated with patient lack of motivation to make lifestyle changes and a lack of willingness to pay for preventative interventions. ${ }^{10}$ Research conducted in the Netherlands in 2013 found that obstacles to the implementation of health promotion activities include the reality that many health promotion programs are not financed or only partially financed for a short period, there are weaknesses in the reimbursement system and subsidies to roll out health promotion programs among general practice physicians. ${ }^{11}$ The paucity of available funds provided exclusively for preventative/promotion services and the amount of capitation received by doctors impacts negatively upon PCPs investment in the work.

The results also show that $8.20 \%$ of PCPs carry out promotive and preventative services in place of practice. This is influenced by several factors such as strong motivation from doctors to implement, supporting facilities and infrastructure, the appreciation of BPJS, supporting regulations and capitation systems that benefit physicians financially.

This is echoed in research conducted in the Netherlands in 2013 which states that the driving factors of the implementation of health promotion activities included personal motivation of the doctors and the existence of a clear policy on the development of health promotion programs. ${ }^{11}$ Recognition/awards from BPJS, the capitation system and promotive and preventative infrastructure facilities should also be made available for the implementation of promotive and preventative services. The availability of these facilities will enable the doctor to carry out promotive and preventative services with patients.

\section{CONCLUSION}

Promotional and preventative services conducted by PCPs in Denpasar are not being implemented optimally. The factors that support the implementation of promotion and preventative services include personal motivation/investment from doctors, supportive promotive and preventative facilities and infrastructure, recognition from BPJS, supporting regulations and capitation systems that benefit physicians financially. Inhibiting factors include low patient willingness, time constraints, limited funds available and low capitation rates.

\section{ACKNOWLEDGEMENT}

We would like to convey thanks to all respondents and informants in this study. 


\section{REFERENCES}

1. Ministry of Health of Indonesia. Peraturan Menteri Kesehatan RI No. 28 Tahun 2014 tentang pedoman program jaminan kesehatan nasional [Ministry of Health Regulation no. 28 of 2014 on the guidelines of the national health insurance program]. Jakarta: Ministry of Health of Indonesia; 2014

2. RCGP. Healthy People: Promoting health and preventing disease. Curriculum Statement. 2013: 1-17.

3. Soetono G, Kurtanty D. Metode membayar dokter layanan primer dalam era JKN [The method of paying primary care physicians in the era of JKN]. 2013: 65.

4. Social Security Administering Agency Denpasar Branch. Laporan kunjungan dan rujukan FKTP se BPJS Kesehatan Cabang Denpasar Tahun 2015 [Report of visit and referral of primary health care facilities on Social Security Administering Agency Branch Denpasar in 2015]. Denpasar: Social Security Administering Agency Denpasar Branch: 2016.

5. Dewi RK. Identifikasi pelayanan promotif pada fasilitas kesehatan tingkat pertama Program Jaminan Kesehatan Nasional [Identification of promotive services in primary health facilities national of health insurance program] [thesis]. Jember: University of Jember; 2015.

6. Cresswell J. Research design: pendekatan kualitatif, kuantitatif, dan mixed, edisi ketiga [Research design: qualitative, quantitative, and mixed approach, third edition]. Yogyakarta: Pustaka Pelajar; 2008.
7. Ribera AP, Mckenna J, Riddoch C. Attitudes and practices of physicians and nurses regarding physical activity promotion in the catalan primary health-care system. European Journal of Public Health. 2005; 15: 569-575.

8. Bock C, Diehm C, Schneider S. Physical activity promotion in primary health care: results from a German physician survey. European Journal of General Practice. 2012; 18: 86-91.

9. Mckenna J, Naylor P-J, Mcdowell N. Barriers to physical activity promotion by general practitioners and practice nurses. British Journal of Sports Medicine. 1998; 32: 242-247.

10. Walter U, Flick U, Neuber A, et al. Putting prevention into practice: qualitative study of factors that inhibit and promote preventative care by general practitioners, with a focus on elderly patients. BMC Family Practice. 2010; 11: 68.

11. Geense WW, van de Glind IM, Visscher TLS, et al. Barriers, facilitators and attitudes influencing health promotion activities in general practice: an explorative pilot study. BMC Family Practice. 2013; 14: 20.

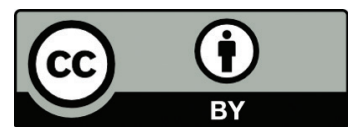

This work is licensed under a Creative Commons Attribution 